\title{
Business process redesign: an action research
}

\section{(Re)desenho de processos de negócios: uma pesquisa-ação}

\author{
Janaina Silveira Vizzon ${ }^{1}$, Luiz Felipe Roris Rodriguez Scavarda do Carmo ${ }^{1}$ (D), \\ Paula Santos Ceryno² (D), Luiza Fiorencio ${ }^{1}$ \\ ${ }^{1}$ Pontifícia Universidade Católica do Rio de Janeiro - PUC-Rio, Departamento de Engenharia Industrial, Rio de \\ Janeiro, RJ, Brasil. \\ ${ }^{2}$ Universidade Federal do Estado do Rio de Janeiro - UNIRIO, Escola de Engenharia de Produção, Rio de Janeiro, \\ RJ, Brasil. E-mail: paula.ceryno@unirio.br
}

How to cite: Vizzon, J. S., Scavarda, L.F; Ceryno, P. S., \& Fiorencio, L. (2020). Business process redesign: an action research. Gestão \& Produção, 27(2), e4305. https://doi.org/10.1590/0104$530 \times 4305-20$

\begin{abstract}
The improvement of business processes is considered important to support companies' competitiveness and sustainability, therefore, being highlighted in the academic community. In this way, the improvement of the organizational processes can be achieved through the business process redesign (BPR), which is considered the most value-added phase in a business process management (BPM) project. However, despite the existence of an extensive literature on the subject of BPR, methodologies or structured procedures that aim to understand the transformation from the "as-is" to the desired "to-be" processes are still scarce. Within this context, to fill this gap in the literature, this study presents the empirical findings and the lessons learnt from an action research with the objective of redesigning the logistic processes of a cultural production enterprise. The empirical study lasted nine months. A synthesis conceptual model for redesigning organizational business processes was proposed based on the literature. This model incorporated three levels (i.e., organizational, business processes and implementation) and provided guidance for conducting the empirical study. Different critical success factors and barriers have been identified and analysed with a focus on organizational, social, and technical dimensions, resulting in contributions to scholars and to practitioners in redesigning business process approaches.
\end{abstract}

Keywords: Operations management; Logistics; Warehouse; Business process.

Resumo: A melhoria dos processos de negócios é considerada importante para o suporte da competitividade e sustentabilidade das companhias, ganhando assim, destaque na comunidade acadêmica. Neste sentido, a obtenção de melhorias nos processos organizacionais pode ser obtida por meio do (re)desenho dos processos de negócios, o qual é considerado a etapa de maior valor agregado dos projetos de gestão de processos de negócios. Contudo, apesar da existência de uma literatura ampla a respeito da temática de business process redesign (BPR), as metodologias ou procedimentos estruturados que visam garantir o entendimento da transformação dos processos "as-is" para "to-be" ainda são escassos. Neste contexto, visando preencher esta lacuna presente na literatura, este estudo apresenta os achados empíricos e as lições apreendidas durante a realização de uma pesquisa ação com o objetivo de (re)desenhar os processos logísticos de uma empresa de produção cultural. O estudo empírico teve duração

Received Sept. 4, 2017 - Accepted May 14, 2018

Financial support: The following research agencies supported this work: Coordenação de Aperfeiçoamento de Pessoal de Nível Superior - Brasil - CAPES (Finance Code 001) Brazilian National Council for Scientific and Technological Development - CNPq (Grant Numbers 3131812014-4, 401522/2014-8, 311757/2018-9). 
de nove meses. Um modelo conceitual de síntese para o BPR foi proposto a partir da literatura. Este modelo incorporou três níveis (i.e., organizacional, processos de negócios e implementação) e guiou a condução do estudo empírico. Diferentes fatores críticos de sucesso e barreiras foram identificados e analisados com foco nas dimensões organizacionais, sociais e técnicas, resultando em contribuições para pesquisadores da academia e para os especialistas da indústria em abordagens de BPR.

Palavras-chave: Gerência de operações; Logística; Armazém; Processos de negócios.

\section{Introduction}

Business Process Management (BPM) is a discipline of organizational management that integrates the strategies and goals of a corporation with the expectations and needs of customers focusing on processes (ABPMP, 2013). BPM is a field of knowledge that interconnects management and information technology and encompasses methods, techniques and tools aiming to design, implement, monitor and analyse the business processes of organizations (Van der Aalst et al., 2003).

The BPM life cycle models systematize the steps and activities to be performed at each stage of the BPM project establishing a managerial practice for the company (Morais et al., 2014). Business process redesign (BPR) is one of the phases of the BPM life cycle. In this phase every business process is analysed, and then it is determined which ones should be reworked, automated, integrated or eliminated (Danesh \& Kock, 2005). BPR has great potential in terms of cost reduction and processing times as well as in customer satisfaction improvement (Vanwersch et al., 2015). The focus on BPR provides an increase in quality and in the services offered by organizations improving their own business processes (Danesh \& Kock, 2005).

Although BPR is a topic widely studied in the academic literature, there is still a lack of methodologies related to this phase (Zellner, 2011; Zellner, 2013; Khosravi, 2016). It is considered as a "black box", since there is a lack of structured methodologies or procedures to ensure the processes transformation understanding from "as is" to "to-be" (Zellner, 2011; Dumas et al., 2013; Vanwersch et al., 2016).

In this context, this article aims to present the empirical findings and lessons learned during the implementation of an action research in the logistics processes management area of a cultural production company. For this purpose, a synthesis conceptual model was developed, offering a guideline for BPR, and which aim is to be used by practitioners or specialists in the area. The research had a total duration of nine months and involved both researchers from academia and professionals of the analysed company. The present study contributes to the literature by offering a detailed methodological support for the generation of improved processes during the redesign step of BPM initiatives addressing as a relevant academic gap (Vanwersch et al., 2016).

This article is organized in six sections, this one being the introduction. Section 2 presents the theoretical arguments and finalizes with a synthesis conceptual model for BPR. Section 3 describes the research method adopted. In Section 4 the empirical study is described and their results are analysed. Section 5 focuses on the best practices, lessons learned, recommendations for its use and provides a synthesis of the results. Finally, the authors' conclusions are enlightened in Section 6. 


\section{Theoretical foundation}

This section presents the theoretical foundation adopted for the development of the research. The topics associated with the BPR are discussed and a synthesis conceptual model is offered at the end.

\subsection{Business Process Redesign (BPR)}

Since the 1990's, with the theme of the business process reengineering (BP-R) in ascension, process improvement has become, in addition to daily task in organizations, a stage of the life cycle approach for processes (Zellner, 2013). Since then, several researchers have started to study methods to improve processes, however the terms used in the literature generated confusion (Hanafizadeh et al., 2009). The most common terms are business process reengineering (BP-R), business process improvement (BPI) and BPR. While the term BP-R refers to radical changes in organizations to consider all aspects of processes restructuring (Limam Mansar \& Reijers, 2007), BPI is about incremental improvements (Zellner, 2013) and BPR refers to improvement programs that meet change's size or pace (Limam Mansar \& Reijers, 2007). However, both terms, BP-R and BPI, may be included in the definition of BPR (Zellner, 2013), being considered BPR subsets, once the redesign can be reached incrementally or radically (Valiris \& Glykas, 1999). In addition, such distinctions are purely academic once practitioners do not tend to do them and often use the term BPR for any programs of business processes improvement (Limam Mansar \& Reijers, 2007).

BPR has as its main objective to create an organizational attitude, instead of a functional / silo attitude, focused on the orientation by processes, as business processes provide the long-term success to businesses and not the products themselves (Hanafizadeh et al., 2009). This comprises the sequence of activities sorted into a stream and the association of skills, equipment and support materials required to execute them (ABPMP, 2013). BPR should be undertaken with a specific business view with the redesign objectives clear in mind (Davenport \& Short, 1990). Its implementation is motivated by performance increases, contributing to reduce organizational costs, to decrease tasks processing times, and to improve products or services quality and employees life quality (Davenport \& Short, 1990; Vanwersch et al., 2015).

Despite the popularity of BPR projects in the industry, a large part of the programs implemented fail (Ranganathan \& Dhaliwal, 2001; Grant, 2002; Albizu \& Olazaran, 2006). To reduce organizational and technical risks associated with BPR initiatives and their implementations, several studies point out the importance of success factors in their business performance (Shen \& Chou, 2010). The success or failure in BPR projects can be explained by the managers positioning facing these factors (Shen \& Chou, 2010).

Al-Mashari \& Zairi (1999) grouped the success factors in five dimensions: change management, competence management and support, organizational structure, planning and project management and information technology infrastructure. Although the success factors may be classified under different optical ranging between authors, the importance of studying them consists in the discovery of the theoretical explanation behind the BPR projects success or failure (Paper \& Chang, 2005).

The organizational environment should support changes so the BPR works (Paper \& Chang, 2005). The engagement should be provided by senior management (Cheng 
\& Chiu, 2008; Shen \& Chou, 2010) to drive change and decrease the resistance between employees (Cheng \& Chiu, 2008). It is essential the customization of an appropriate methodology which guides the BPR principles (Paper \& Chang, 2005). Additionally, the information sharing among the members of the work team is essential (Paper \& Chang, 2005) This communication must be effective (Shen \& Chou, 2010) and, in this case, information technology has an important role in the process of change (Attaran, 2004). Shen \& Chou (2010) point out as success factors in the BPR implementation the identification of opportunities for the BPR and the involvement of employees.

The main barriers for BPR refers to the absence or inadequacy of success factors (Al-Mashari \& Zairi, 1999). The issues related to resistance to change, fear, lack of understanding and commitment, inadequate approach of BPR and organizational culture are barriers to the BPR success (Abdul-Hadi et al., 2005). These barriers involve the practice of change management and its revision is of extreme importance to ensure the completeness and reliability of business processes (Huq et al., 2006).

In the literature it is agreed that there is still a gap regarding the existence of methodologies related to BPR, also named "act of process improvement" (Zellner, 2013), although there are many attempts to establish framework for BPR (Vergidis et al., 2006). In the majority of the transformation approaches to move from the "as-is" to the "to-be" process the techniques used are considered "black boxes" lacking methodological support to practitioners (Netjes, 2010).

BPR methodologies presented in the literature have different steps that fall within the division of three levels of interest as the classification offered in Harmon (2014): organizational, business processes and implementation. The organizational level encompasses the definition of organizational needs for BPR implementations project (Berio \& Vernadat, 2001). The business processes level involves the understanding and analysis of current processes and design of future processes (Adesola \& Baines, 2005). The implementation level relates to the enforcement and monitoring of the "to-be" processes (Adesola \& Baines, 2005).

Analysing BPR methodologies found in literature (e.g. Sharp \& Mcdermott, 2001; Reijers, 2003; Adesola \& Baines, 2005; Yoo et al., 2007; Mendling et al., 2010; Netjes, 2010; Dumas et al., 2013; Khosravi, 2016), it appears that the business processes level provides procedures more generic at the tactical level for the processes "to-be" creation (e.g., operations cases or guidelines to (re)design) or deal with the flowcharts transformation from "as-is" to "to-be" at the operational level. As an example of tools to support the transformation processes, there are rules of operations in process modelling software, SIPOC - Supplier, Input, Process, Output and Customer (e.g., a tool for identifying important elements of a process improvement project prior to the work beginning, Montevechi et al., 2008) and POP - Standard Operating Procedure (e.g., a set of instructions that standardize the operating procedures detailing the actions necessary for the realization of events, Schackart, 2008). Among the methodologies whose approach are rules for operations in modelling software there is a consensus about the use of these rules appointed by the literature as "best practices" (Reijers \& Limanmansar, 2005; Netjes, 2010) where one of the notations most commonly found is the BPMN (Business Process Modelling Notation). The BPMN facilitates the understanding of the process modelled and is a powerful tool capable of modelling complex business processes (França et al., 2013). Among the techniques of creativity mentioned, brainstorming and "thinking outside the box" are useful in supporting the creation of "to-be" processes (Netjes, 2010). 
Although there is a distinction between the analysed methodologies approaches and not all of them provide a framework to assist practitioners, all allow an overview about the topic of BPR. Still, it appears that there is no line between the main techniques and tools used in the BPR literature, corroborating with Zellner (2011).

\subsection{Synthesis conceptual model for BPR}

The synthesis conceptual model for BPR is presented in this subsection, as illustrated in Figure 1. This is based on the BPR methodological approaches available in the literature. The objective of this model is to provide support and suit as a guide to specialists in the area of BPR approaches. The model seeks to provide a methodological support composed by levels for the processes transformation from current "as-is" processes (inputs) to future "to-be" processes (outputs). The Conceptual model for BPR model is composed by three levels: (i) organizational, (ii) business processes and (iii) implementation (adapted from Berio \& Vernadat, 2001; Adesola \& Baines, 2005; Harmon, 2014). Each level of interest has three main components: the key issues related to the processes, the tasks for its implementation (i, ii, iii) and the techniques used for its operationalization (Grover \& Malhotra, 1997).

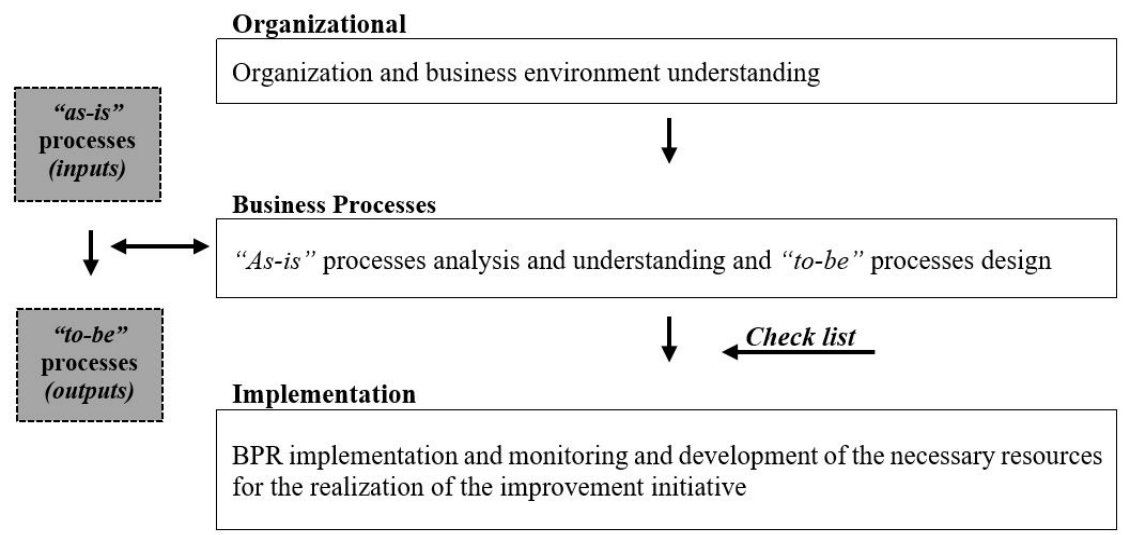

Figure 1. Synthesis conceptual model for BPR. Source: Authors.

BPR has three distinct forms for the starting point: the current processes ("as-is"), the reference models, which represent the state of the art for the procedure in question and are usually developed by consultancy or information technology firms, and the processes started from scratch (Dumas et al., 2013). As a BPR result, there are the future processes ("to-be") that have been redesigned to best accomplish the organizational objectives and to fit into their strategy (Jeston \& Nelis, 2006).

The first level of the synthesis conceptual model is the organizational that encompasses the understanding of the organization (Berio \& Vernadat, 2001) and the business needs (Adesola \& Baines, 2005). At this level the issues related to the organizational strategy and the business environment are addressed. The strategic considerations allow the contextualization of the goals and challenges under the processes analysis (ABPMP, 2013). The considerations about the business allow the understanding of the organizational market performance, the factors that affect the business strategy, and the information on customers and suppliers (ABPMP, 2013). Questions are raised at this level about the senior management involvement level, the 
strategic objectives scope through BPR (Grover \& Malhotra, 1997), the change interpretation by the people who are concerned and the associated functional areas, the leaders responsible for delivering the processes results, the processes functions in the current business environment and their adaptation to changes, the processes risks and forms of adaptation to surpass these risks (ABPMP, 2013). Still, the issues related to the definition of the procedures necessary for the organizational strategies implementation, the skills needed to processes and the stakeholders' contributions to develop them to govern the organizational level (Jeston \& Nelis, 2006). The tasks to be carried out concern to the vision and the organizational strategic objectives understanding (ABPMP, 2013), the competitors and stakeholders analysis, the evaluation of current practices in the company (Adesola \& Baines, 2005), the establishment of goals to processes, the customers' requirements (Kettinger et al., 1997) and the processes goals definition (Adesola \& Baines, 2005). The fundamental techniques for this level implementation involve gathering information (ABPMP, 2013), the SWOT analysis, benchmarking, the best practices analysis and the cause and effect analysis (Adesola \& Baines, 2005), research with stakeholders, structured interviews, costs analysis, benefits and risks, "out-of-the-box thinking" (Kettinger et al., 1997), project management and change management (Grover \& Malhotra, 1997).

The second level of the synthesis conceptual model is the business processes where the main issues related to the understanding and analysis of the "as-is" processes and the "to-be" processes are placed (Adesola \& Baines, 2005). The entries in this level are constituted by the organizational level and the "as-is" processes (ABPMP, 2013). The (re)design consists in the identification of the "as-is" processes elements and in the tasks definition aiming to create a new vision, based on the goals established for the "to-be" processes (Grover \& Malhotra, 1997), and also aiming to eliminate problems and to increase efficiency (ABPMP, 2013). This level still involves the technical and social organizational (re)design (Grover \& Malhotra, 1997), which is guided by the topics relating to the existence of current processes and their objectives, the identification of problems in processes, the knowledge of stakeholders and their responsibilities (Von Rosing et al., 2014), the processes fitting in the organizational value chain and the support of its strategic objectives (ABPMP, 2013). They are also addressed issues related to the identification of sub processes, activities and stages of processes, resources used, the operation of information flows, the main strengths and weaknesses of the processes analysed, the operationalization and operation of processes, the use of information technology to its processing, the human and technical resources needed to new processes, the objectives to be achieved by BPR (Grover \& Malhotra, 1997) and the measures of performance associated with the processes (re)designed (Jeston \& Nelis, 2006). The tasks performed at this level involve the analysis, the understanding of the architecture and the measurement of the procedures performance, the identification of value added activities to processes and opportunities for its improvement (Grover \& Malhotra, 1997), the identification of the activities focus and the IT requirements, the processes modelling, the "to-be" processes validation and its performance estimation (Adesola \& Baines, 2005). The tasks operationalisation required to (re)design the "as-is" processes is carried out by the employment of techniques, such as the flowcharts analysis, the value chain analysis, the processes values and cycle time analysis, performance measurements, modelling, documentation (Grover \& Malhotra, 1997), the curves ABC analysis, as well as sessions of creativity, brainstorming (Adesola \& Baines, 2005), "out-of-the-box thinking", process mapping and simulation (Kettinger et al., 1997). 
The third level of the synthesis conceptual model refers to the implementation and monitoring of the processes (re)designed (Adesola \& Baines, 2005) and to the development of the resources necessary for the realization of the improvement initiative (Harmon, 2015). The entries at this level are the business process outputs: the "to-be" processes and a checklist containing questions concerning the preparations to be made and the solutions to be appointed prior to the effective implementation of new processes (Jeston \& Nelis, 2006). In the checklist the topics are related to the transformation initiative that is divided in projects and in teams, the teams' training (ABPMP, 2013), the acquisition and the interaction of technical and social resources and the employees' resistance to change (Grover \& Malhotra, 1997). Considered the most difficult level of BPR (Furey, 1993), the technological and the social plans developed earlier are then implemented (Grover \& Malhotra, 1997). The issues that underpin the implementation involve the organizational, methodological, social and technological aspects (Paper \& Chang, 2005). At this level the ways to ensure a smooth transition and the mechanisms to be established are questioned aiming at the resolution of unforeseen problems, the monitoring and evaluation of progress (Grover \& Malhotra, 1997) and the locations in which the documented processes can be found (ABPMP, 2013). The tasks include planning the "to-be" processes implementation, the communication about the change, the technological development, employees training, the revision of the organizational approach, the establishment of goals for performance, the transformation plan implementation (Adesola \& Baines, 2005), driving tests and pilot projects in the new approach, the continuous monitoring of results (Grover \& Malhotra, 1997), among others. The techniques that support this level involve project management and change management, performance monitoring (Grover \& Malhotra, 1997), tests on information technology systems and employees training (Kettinger et al., 1997).

\section{Research method}

The methodology adopted for conducting the empirical study is an action research. The empirical study uses a scientific approach to study the problems resolution, it is participative, occurs simultaneously with the action and the events are performed sequentially, through an approach that aims at the solution of impasses, which is in line with the characteristics of an action research described in Coughlan \& Coghlan (2002), Gutierrez et al. (2015), and Carvalho et al. (2014, 2015, 2016).

The synthesis conceptual model for BPR presented in Figure 1 provided a support for the development of the research protocol, which embraces three levels: (i) organizational, (ii) business processes and (iii) implementation, as described next.

\subsection{Organizational level}

The action research began with the understanding about the organization, its strategy, goals and objectives, followed by understanding about the business environment regarding the logistics department, which is the object of study in this article. Concomitantly, the organizational objectives and performance measures for the areas under analysis were obtained, as well as best practices existing in the organization being incorporated by the same areas. 
The organizational level started in month 1 of the total of nine months of the empirical study. It counted with the involvement of the top management of the logistics department via weekly meetings (four in total) to define the areas that would be studied and to ensure the organizational strategic alignment in these areas. The top administration was composed by managers directly involved in the logistics processes: the supply chain director and the logistics manager.

The participants of the BPR initiative were identified after the definition of the areas that would be analysed (i.e., Materials, Special Effects, Events and Spare Parts warehouses). This team was composed by processes analysts, processes owners and by the management level.

Subsequently, a benchmarking was conducted to compare the performance of the "as-is" processes with similar processes in different areas within the organization. The internal benchmarking was based on internal reports of the areas (e.g., performance indicators, interviews with members of the team, different initiatives of BPR and visits in loco at different operations). Its goal was to identify what had been implemented and defined earlier as standard by the headquarters, making possible the adaptation of the existing "as-is" processes to the established pattern. Additionally, this research step counted with the results of an external benchmarking conducted in 2014 in which segments of similar businesses of other companies were analysed.

Concomitantly with the assessment of current practices in the organization, it was carried out an analysis of the customers and other stakeholders needs for the warehouses under study. New interviews were conducted with logistics top administration aiming to understand the areas peculiarities and stakeholders' demands using as a guide the issues presented within the organizational level of the synthesis conceptual model presented in subsection 2.2. Meetings were also conducted with the stakeholders of the processes to provide an alignment between the areas expectations and needs and also a better relationship and information sharing between them.

The analysis and conducted meetings and interviews, as well as managerial data collected at this level, have enabled to contextualize the BPR team in the context of organizational and business environment allowing the group to understand the necessary requirements for the execution of the next levels of the synthesis conceptual model for BPR.

\subsection{Business Processes Level}

At this level the BPR team sought to understand and analyse the context of the warehouses "as-is" processes as well as their architectures and goals. The information collected at the organizational level, operated as an input for its development, which lasted five months. This level defined for each of the warehouses analysed the defined modelling participants, who constituted by the responsible for the processes instances, the owners of the processes, the analysts of processes and the management responsible for defining monitoring and control mechanisms.

Data gathering was conducted by means of observation in loco and documents analysis, such as: spreadsheets, performance indicators, procedures manuals, screen shots of software and photographic records to understand the context of logistics operations in terms of processes, layout, productivity and information technology. Semi-structured interviews were held with the manager and coordinators of logistics and with the stakeholders of the processes, using as a guide the issues presented within the business processes of the synthesis conceptual model represented by 
Figure 1. During the meetings, it was possible to establish performance objectives and targets for the development of processes according to organizational strategies and aligned to the required service level and the storage policy.

Interviews with the warehouse operators from the Materials warehouse were conducted weekly. The "as-is" flowcharts and the documents collected were then analysed. From the analyses and the needs identification to be implemented by the area, opportunities for improvement were found enabling the creation of "as-is" processes. Weekly interviews with three supervisors and warehouse operators were performed in the Special Effects warehouse. The documents collected and the "as-is" flowcharts were analysed. Face-to-face interviews, phone or conference meetings with a supervisor and the coordinator of the warehouses were performed in the Events and Spare Parts warehouses.

In the cases of non-documented processes, these were mapped from scratch. From brainstorming sessions and on -site observations, opportunities for improvement were identified and the processes were mapped and (re)designed by the BPR team. First of all, the SIPOC was created and then the modelling was developed, which was performed by the BPR team in software Visio using BPMN notation. The "to-be" processes were initially validated at operational level by the owner of the processes, and then documented with the tool POP. Finally, a second validation of all documentation created was performed by the coordinator and logistics manager.

\subsection{Implementation level}

The "to-be" processes created previously were implemented and monitored at this level. The organizational, methodological, social and technological factors inherent to this level were taken into account through the use of the check list provided in Figure 1, which provides the necessary steps to the implementation of the BPR initiative.

This level lasted three months and counted on the involvement of logistics top administration to ensure the stakeholders involvement in the processes of the analysed warehouses with the BPR initiative. In addition, this level counted with the engagement of the IT consultancy responsible for the new software implementation in the organization.

In the four warehouses analysed pilot projects for the implementation of the "to-be" processes were developed to serve as experiments to the actual implementation and to provide feedback with relevant and value added information for the processes improvement. The development of the pilot projects involved previous studies and analysed the human and physical resources, the IT needs for the "to-be" processes implementation as well as the availability of budget and processes performance monitoring tools. In addition, tests were performed for the installation and configuration of IT systems in the four warehouses aiming to the adhesion of systems to the "to-be" processes. The tests and the implementation of the systems were conducted in collaboration with the IT consulting firm hired by the organization for the implementation of the software WMS - Warehouse Management System.

Trainings with the executors of the "to-be" processes were performed in the four warehouses to allow the understanding of the processes and their capacity for handling with the tools required. The trainings involved reading the standard structure of documents created on the previous level of the synthesis conceptual model for BPR and also conducted by the IT company hired for the implementation of WMS. 
A contingency plan was developed in the Materials warehouse to prepare the collaborators in the new processes.

\section{Empirical study}

This section presents the results of the empirical study in four parts. The first focuses on the object of study and the others on the three levels defined in the synthesis conceptual model for BPR presented in Figure 1: organizational, business processes and implementation.

\subsection{The object of study}

The object of study is a cultural production company with more than ten thousand direct and indirect employees. The logistics department is located within the division of Supply Chain and is composed by a manager, three coordinators, four warehouses supervisors, four logistics planners and more than 100 collaborators, among employees and third parties. Recently, the organization developed a strategic plan for its logistics whose actions for implementation and review comprises a long-term horizon. This plan was motivated by the need of a better ability to respond to the logistics challenges of the company with the scenario of expansion and increased demand for its products.

As a result of this strategic plan, improvements have been implemented annually in the organization. The study of this article was performed during the implementation of a project focused on organizational business processes, with the objective of improving the response capacity of the logistics department processes and aligning it within the organizations' strategic objectives.

\subsection{Organizational level}

The warehouses selected by top administration to make part of the empirical study perform the management of materials and equipment in the organization and are part of the 12 warehouses under the responsibility of the logistics department. Its main stakeholders are the sectors: Purchasing, Accounting, Scenery Production, Engineering and IT.

Detailing the specificity of each warehouse, the Materials warehouse has been benefited by the recent deployment of an IT software to control and monitor the management of materials as well as being a tool capable of measuring the performance of the processes assisting in decision-making. Although the new system software warehouse management was available for use in the area, the feature was not used for the processes of receipt. With respect to the Special Effects warehouse, it is important to emphasize that this warehouse reflected the characteristic of the organization's expansion with the acquisition of new areas aiming at the fulfilment of new demands by the logistics department. The management processes performed by the warehouse were still not aligned to the logistics department in the company. Finally, the Events and the Spare Parts warehouses expressed the subsidiaries no standardization of logistics network when compared to the headquarters.

As a result of the recent strategic planning, the organizational environment in which this study was carried out experienced a context favourable to change. It was observed 
since the beginning the involvement and engagement of logistics top administration with the BPR initiative. It was evident that the management of the logistics processes has become paramount in organization to ensure the fulfilment of new demands, align the processes to available resources and meet the strategic direction.

The commitment of top administration was the key enabler, functioning as a catalyst of change in the collaborators, corroborating with Cheng \& Chiu (2008), reducing the fear of failure inherent to people, as emphasized by Paper \& Chang (2005). Furthermore, the top administration played a fundamental role in the alignment of the warehouses with the business strategy, ensuring the understanding of organizational goals and the convergence of processes to the goals of the company, in line with the outlined by Morais et al. (2014). This enabler was also responsible for directing, monitoring and controlling activities related to processing, thus corroborating Paper \& Chang (2005).

As a result, changes and improvements in processes were necessary, requiring the existence of a collaborative environment in which employees were involved and knew from the beginning what would be their roles and responsibilities in the process of change, as described by Paper \& Chang (2005). Effective communication with stakeholders of processes and with IT consulting firm responsible for the implementation of the WMS system was essential for the understanding of the issues and solutions of the BPR project and regular communication of your progress, as say Cheng \& Chiu (2008).

This level ended with the clarification of organizational needs, understanding their goals and strategies and understanding about the business environment of warehouses. Generally, it was understood what would be the requirements for the development of the next levels of BPR.

\subsection{Business processes level}

In the Materials warehouse, part of the processes was not mapped or documented and other was not bonded to the new reality of the organization. In addition, some of the indicators were not employed properly and others could be created. There were indicators that could be created from the moment in which the WMS software become enabled, allowing the record of the major events of the processes of receipt. The diagnosis of the area identified the existence of several bottlenecks in the process of receiving, such as: the implementation of activities whose scope was not the department of logistics, the absence of policies defining responsibilities and deadlines in cases of non-conformities, low automation with the generation of many physical documents, the inadequacy of the layout area and the conference structures. In addition, it was observed an excess of bureaucracy for the receipt recording in IT systems and for the monitoring of pending issues along with the main stakeholders of the logistics department influencing the productivity of the team and the standardization and sharing of data, which were recorded on spreadsheets or in e-mails.

The mapped "as-is" flowcharts used as a point of departure to redesign the processes were not conformity, since some were modelled in Visio software and others in Bizagi software. This fact was considered a barrier to the BPR project once the Bizagi software was not available for use in the organization and, therefore, modifications in the process mapping could not be carried out. It was necessary the transcription of the "as-is" flowchart in Bizagi to the Visio so that processes could be reformulated into "to-be" processes and validated. 
In the Special Effects warehouse were analysed "as-is" flowcharts and mapped the processes whose documentation did not exist from scratch. The analysis of business processes revealed the existence of inconsistencies in the new area incorporated by the department of logistics, such as: the lack of scope for defining the area responsibility, the low integration and communication with the stakeholders of the processes and the lack of formalized and controlled processes regarding its implementation. In addition, although the area generated relevant information, which were recorded mainly in spreadsheets, there was a system of performance indicators implemented to assess the operations' performance, making difficult the decision-making and area strategic alignment. The "to-be" processes and the indicators created have been validated by the modelling team and revalidated by the logistics top administration.

In the Events and the Spare Parts warehouses the analysis of the processes identified that the processes performed by the subsidiaries were not adhering to the IT software used by the organization and had not been standardized according to the logistics network standard defined by the headquarters. In addition, policies for storage and service level agreement had not been defined for both warehouses, demanding its creation that were based on the headquarters standard. There were existing indicators that measured the processes performance. The "as-is" processes of the two warehouses were aligned within the current practices in the organization and (re)designed in the light of the internal benchmark. The "to-be" processes and the indicators created have been validated by the modelling team and revalidated by the logistics top administration.

This level contemplated the information gathering and analysis of data involving the "as-is" processes of four warehouses. The stakeholders of the processes, constituted by suppliers, customers and functional areas of interface were involved in the creation of a new vision for the "as-is" processes and in the definition of new roles and responsibilities. The meetings to analyse the "as-is" processes and to suggest changes were in line with the objectives defined for the "to-be" processes. This analysis also allowed the identification of problems, such as performance goals that were not met, failures in interactions with stakeholders, variations in process and bottlenecks.

One of the key factors for the success of this level was the support and commitment of the executive leadership, encouraging changes and guiding people for the implementation processes, as already pointed out by Paper \& Chang (2005). In addition, the participation of employees, who had knowledge of their roles in the process of change made easier the analysis and the cases studied (re)design, as corroborated by Paper \& Chang (2005), and fostered the existence of a collaborative environment between the BPR team and the executioners of the processes, as previously indicated by Al-Mashari \& Zairi (1999).

The creation of an organizational culture favourable to changes was provided by a vision of transformation designed by managers to employees to encourage innovation and information sharing between the BPR team and its stakeholders, a fact also presented by Paper \& Chang (2005). In addition, clear communication of the business strategy by the top administration allowed the understanding of the existing processes and the goals to be achieved enabling the strategic alignment of the processes within the organizational goals, as also pointed out by Attaran (2004).

This level ended with the processes of the four warehouses (re)designed and aligned to the organizational objectives and the IT systems available in the company depicting the reality of each of the areas analysed and in accordance with the best 
internal practices. As a result, it was created a structure of standard documents serving as a guide for the implementation of the activities belonging to the business processes analysed and also the acceptance of the BPR project by employees and stakeholders.

\subsection{Level of implementation}

In the Materials warehouse the processes (re)design resulted in the creation of a new functional area called Advanced Receive Station, in charge of the process implementation whose responsibility was not of the logistics department. Its creation demanded a staff restructuring to be located in the new area as well as training, contingency plans, tests and pilot projects for implementation. The roles and responsibilities of the employees involved in the processes belonging to the new area were defined in a cautious way, due to the stakeholders' resistance regarding the incorporation of new assignments and the BPR project. This barrier required the engagement of the logistics top administration for convincing and mobilizing the accounting and procurement areas in favour of the project.

The set of standard documents created in the Materials warehouse has operated as a guide for training the staff in the new area. In addition, the development of a contingency plan was essential to support the transition of the new collaborators.

In the Special Effects, Events and Spare Parts warehouses, the "to-be" processes were implemented as they were being validated by managers. The (re)design of Special Effects warehouse processes allowed the formalisation and control of processes that run through the area as well as the definition of the roles and responsibilities of the stakeholders involved. In the Events and Spare Parts warehouses the (re)design ensured the standardization of processes as the standard stipulated by the headquarters.

In all warehouses the training of employees was important to familiarize themselves with the new features and the development of greater ability in solving problems and in making decisions, as also attested by Paper \& Chang (2005). In addition, the training consisted in a powerful tool of cultural transformation by increasing the awareness and understanding of the business environment by employees, ratifying Paper \& Chang (2005).

The four areas analysed do not exploited the full potential of the software available in the organization, however, the establishment of a suitable support was made possible by the involvement of the IT consulting company in the BPR project through the completion of tests and calibrations in the WMS members to the reality of the areas. The development of an effective IT infrastructure was essential to facilitate the information sharing between the different functional areas participants in the same business process, as also pointed out by Attaran (2004).

The implementations in four warehouses counted with, in addition to the employees training, the human involvement of the IT consulting firm hired, which were consulted during the various stages of implementation. The awareness and empowerment of employees were made possible by the top administration that looked to its role in the creation of a workspace with greater autonomy, corroborating the findings of Paper \& Chang (2005). The support of the top administration and the encouragement of employees' involvement was manifested in the logistics manager meetings with the operational teams of all warehouses in which the processes (re)designed have been implemented. 
The top administration commitment for managing change was essential to decrease the resistance of collaborators, aspect already approached by Parkes (2016) and to establish a collaborative environment, corroborating Paper \& Chang (2005). The support of the top administration embraced the definition of a plan which aimed at ensuring the quality of the new area implementation, the sponsorship to its creation and acceptance of recommendations arising from the BPR team. Furthermore, the incentive to change by top administration and the understanding that the project was a mean of ensuring the organizational competitiveness and improvement of services was essential for the implementation of the BPR project, ratifying Cheng \& Chiu (2008).

The management of change was crucial in all areas in which the BPR initiative was inserted. However, the Special Effects warehouse, which was a new area whose management style was different from that practiced by the logistics department and whose culture was not familiar to transformations, it was necessary the development of a culture geared to changes where the existing values and beliefs were no longer appropriate to the environment that would be (re)designed, corroborating Al-Mashari \& Zairi (1999). In the Materials, Events and Spare Parts warehouses, which were already part of the Logistics and had already passed by previous changing initiatives, change management occurred in an easier way. In those areas the organizational environment was supported by attitudes inherent in the BPR initiatives, such as the collaboration between teams at work, cooperation and coordination between contributors and the empowerment of employees, in line with the findings of Al-Mashari \& Zairi (1999). The cultural management had, therefore, as also shown by Parkes (2016), a primary role to try to maximize the chances of success of the BPR initiative.

It has been observed that the effective communication of managers towards collaborators consisted also in an important success factor for the successful implementation of the new area, a fact also explored by Cheng \& Chiu (2008). In addition, it was crucial the existence of sufficient resources and budget for the completion of works aimed at the physical installation of the new area, the appropriateness of IT systems to the "to-be" processes and the employees training in new processes, corroborating Paper \& Chang (2005).

The "to-be" processes created for the warehouses analysed in the empirical study resulted in organizational, technical and social changes for the company. The implementation level refers to the realization of the "to-be" processes taking into account the coordination between the processes owners and others aspects such as the management of change and training aimed at the implementation of new processes.

This level ended with the processes of the four warehouses implemented enabling the clear understanding of the logistics activities performed by employees and stakeholders. There was acceptance by part of employees that the changes provided to support the organizational strategic goals and to enable a better processes visualization performed by areas. In addition, there was a better understanding about the tools implemented and the changes imposed by the use of the standard documents created. Still, the BPR methodology used worked as a meeting point between the collaborators to promote a processes routine analysis and helped to develop an organizational culture geared to continuous improvement. 


\section{Discussions}

Table 1 presents a summary of the Organizational, Business Processes and Implementation levels discussed in this action research, where the context and main barriers associated with each of the four warehouses were analysed, as well as the good practices and outcomes common to them at each of the levels of the synthesis conceptual model for BPR.

As highlighted in Table 1, the commitment of top management was the key enabler at the organizational level to conduct the BPR initiative. The support of the logistics top administration area was as driver for change within the collaborators, as presented by Cheng \& Chiu (2008), reducing the fear of failure inherent to people, as emphasized by Paper \& Chang (2005). Furthermore, the top administration had a role to align the functional areas within the business strategy and to ensure the complete understanding of organizational goals and processes convergence to the company's goals, as described by Morais et al. (2014). This enabler was also responsible for directing, monitoring and controlling activities related to transformation, thus corroborating Paper \& Chang (2005).

One of the lessons learned at the business processes level was the support and commitment of the executive leadership to encourage the changes aimed at maintenance of the organization's competitiveness, as corroborated by Cheng \& Chiu (2008) and to guide the processes for people implementation, as mentioned by Paper \& Chang (2005). According to Parkes (2016), a good management of the processes (re)design project by the logistics top administration area was essential for a successful implementation phase. In addition, the collaborators participation, who had knowledge of their roles in the change process, in a spontaneous and accessible way, facilitated the analysis and (re)design of the cases studied, as corroborates Paper \& Chang (2005). Furthermore, it fostered the existence of a collaborative environment between the (re)design team and the processes executioners, as validates Al-Mashari \& Zairi (1999). 
Table 1. Synthesis of the results obtained in the Organizational, Business Processes and Implementation levels.

\begin{tabular}{|c|c|c|c|}
\hline & Materials Warehouse & Special Effects Warehouse & $\begin{array}{l}\text { Spare Parts } \\
\text { Warehouse }\end{array}$ \\
\hline \multirow[t]{4}{*}{ Organizational Level } & $\begin{array}{l}\text { Context: (i) Misuse of IT software } \\
\text { available in the organization; } \\
\text { (ii) Processes non-adherent to the reality }\end{array}$ & $\begin{array}{l}\text { Context: (i) New warehouse acquired by } \\
\text { the logistics department; (ii) Non- } \\
\text { standard processes according to best } \\
\text { organizational practices }\end{array}$ & $\begin{array}{c}\text { Context: (i) Subsidiary incorporated by the } \\
\text { logistics department; (ii) Non-standard processes } \\
\text { according to the benchmark area stipulated by } \\
\text { the headquarters }\end{array}$ \\
\hline & Barriers: Not identified & Barriers: Change-resistant culture & Barriers: Not identified \\
\hline & \multicolumn{3}{|c|}{$\begin{array}{c}\text { Best Practices: (i) Alignment with business strategy; (ii) Support from top administration; (iii) Collaborative environment; (iv) Effective } \\
\text { communication }\end{array}$} \\
\hline & \multicolumn{3}{|c|}{$\begin{array}{l}\text { Results: (i) Understanding of organizational objectives and strategies; (ii) Understanding of the business environment; } \\
\text { (iii) Understanding the requirements required for the next phases of the (re)design project }\end{array}$} \\
\hline Business Processes Level & $\begin{array}{l}\text { Context: (i) Execution of activities whose } \\
\text { scope was not the logistics department; } \\
\text { (ii) Lack of policies defining } \\
\text { responsibilities and deadlines in cases of } \\
\text { non-conformities in receipts; (iii) Low } \\
\text { automating of the receiving process with } \\
\text { the generation of many physical } \\
\text { documents; (iv) Inadequacy of the area } \\
\text { layout and conference structures } \\
\text { contributing to spread ergonomic } \\
\text { problems; (v) Excessive bureaucracy to } \\
\text { record receipt in IT systems; } \\
\text { (vi) Excessive bureaucracy to follow up } \\
\text { on pending issues with key stakeholders; } \\
\text { (vii) Difficulty of data standardization and } \\
\text { sharing }\end{array}$ & $\begin{array}{l}\text { Context: (i) Undefined scope of area } \\
\text { responsibility; (ii) Low integration and } \\
\text { communication with process } \\
\text { stakeholders; (iii) Lack of formalized } \\
\text { processes; (iv) Difficulty of data } \\
\text { standardization and sharing; ( } v \text { ) Lack of } \\
\text { performance indicators }\end{array}$ & $\begin{array}{l}\text { Context: (i) Processes that are not adherent to } \\
\text { the IT software used by the organization; (ii) Non- } \\
\text { standard processes according to the benchmark } \\
\text { area stipulated by headquarters; (iii) Processes } \\
\text { not portraying the areas reality; (iv) Lack of } \\
\text { storage policies and service level agreement; } \\
\text { (v) Lack of performance indicators }\end{array}$ \\
\hline
\end{tabular}


Table 1. Continued...

\begin{tabular}{|c|c|c|c|}
\hline & Materials Warehouse & Special Effects Warehouse & $\begin{array}{l}\text { Spare Parts } \\
\text { Warehouse }\end{array}$ \\
\hline & $\begin{array}{l}\text { Barriers: Incompatibility of the tool used } \\
\text { by IT consulting company and the } \\
\text { (re)design team for the creation of "to-be" } \\
\text { processes }\end{array}$ & Barriers: Change-resistant culture & $\begin{array}{l}\text { Barriers: Incompatibility of the tool used by IT } \\
\text { consulting company and the (re)design team for } \\
\text { the creation of "to-be" processes }\end{array}$ \\
\hline & \multicolumn{3}{|c|}{$\begin{array}{c}\text { Best Practices: (i) Alignment with business strategy; (ii) Support from top management; (iii) Change management; (iv) Collaborative } \\
\text { environment; (v) Employees involvement; (vi) Effective communication; (vii) Project management; (viii) Opportunities identification for } \\
\text { business processes (re)design; (ix) Detailed processes models }\end{array}$} \\
\hline & \multicolumn{3}{|c|}{$\begin{array}{l}\text { Results: (i) (Re)designed processes; (ii) Processes aligned with organizational objectives, available IT systems and internal best } \\
\text { practices; (iii) Creation of a standard document structure for business processes; (iv) Acceptance of the (re)design project by } \\
\text { employees and stakeholders }\end{array}$} \\
\hline \multirow[t]{4}{*}{ Implementation Level } & $\begin{array}{l}\text { Context: (i) Formalisation of "to-be" } \\
\text { processes; (ii) Creation of the new } \\
\text { functional area called Advanced } \\
\text { Receiving Station; (iii) Restructuring of } \\
\text { staff in the new area; (iv) Training of } \\
\text { employees; (v) Creation of contingency } \\
\text { plans; (vi) Running tests on the WMS } \\
\text { software; (vii) Execution of pilot } \\
\text { implementation projects }\end{array}$ & $\begin{array}{l}\text { Context: (i) Formalization and control of } \\
\text { "to-be" processes; (ii) Definition of the } \\
\text { roles and responsibilities of the } \\
\text { stakeholders involved; (iii) Training of } \\
\text { employees; (iv) Running tests on the } \\
\text { WMS software; (v) Execution of pilot } \\
\text { implementation projects }\end{array}$ & $\begin{array}{l}\text { Context: (i) Standardization of "to-be" processes } \\
\text { according to the benchmark area stipulated by } \\
\text { the headquarters; (ii) Training of employees; } \\
\text { (iii) Running tests on the WMS software; (iv) } \\
\text { Execution of pilot implementation projects }\end{array}$ \\
\hline & Barriers: Stakeholders resistance & Barriers: Change-resistant culture & Barriers: Not identified \\
\hline & \multicolumn{3}{|c|}{$\begin{array}{c}\text { Best Practices: (i) Alignment with business strategy; (ii) Support from top management; (iii) Change management; (iv) Collaborative } \\
\text { environment; (v) Employees involvement; (vi) Effective communication; (vii) Project management; (viii) Training; (ix) Resources and } \\
\text { sufficient budget; (x) Effective IT infrastructure }\end{array}$} \\
\hline & \multicolumn{3}{|c|}{$\begin{array}{l}\text { Results: (i) Processes (re)designed implemented; (ii) Understanding of logistics activities by employees and stakeholders; (iii) Better } \\
\text { visualization of the processes by the areas; (iv) Acceptance of organizational change by employees; (v) Better understanding of IT } \\
\text { tools and changes implemented; (vi) Use of standard self-learning document structure on "to-be" processes; (vii) Promotion of a } \\
\text { processes analysis routine; (viii) Development of an organizational culture oriented towards continuous improvement }\end{array}$} \\
\hline
\end{tabular}


Table 1 also points, from the business processes level view, the existence of an organizational culture favourable to changes that was provided by a vision of transformation designed by managers to employees to encourage innovation and information sharing between the (re)design team and its stakeholders, as describes Paper \& Chang (2005). In addition, a clear communication about the business strategy developed by top administration allowed the understanding of the existing processes and its goals to be achieved to obtain the strategic processes alignment to organizational goals, as clarified in Attaran (2004).

At the implementation level, the change management was crucial in all areas in which the initiative of business processes (re)design has been inserted. In the meantime, at the Special Effects warehouse, which was a new area whose management style was different from the one practiced by the logistics department and whose culture was not favourable to changes, it was necessary the development of a culture related to transformation from scratch by the top administration, in which the values and the pre-existing beliefs were no longer appropriate to the environment that would be (re)designed, as corroborates Al-Mashari \& Zairi (1999). In the Materials, Events and Spare Parts warehouses, which were already part of the logistics department and had already undergone previous transformation initiatives, the change management occurred more easily. In these areas, the environment was supported by organizational attitudes inherent to the business processes (re)design initiatives, such as the collaboration between teams at work, cooperation and coordination between contributors and the empowerment of employees, as quoted by Al-Mashari \& Zairi (1999). The cultural management had, therefore, as presented by Parkes (2016), a primary role to try to maximize the business processes (re)design initiative success chances.

Figures 2 and 3 illustrate one example of the business processes (re)design with an "as-is" flowchart and a "to-be" flowchart representing the receiving process at the Materials warehouse.

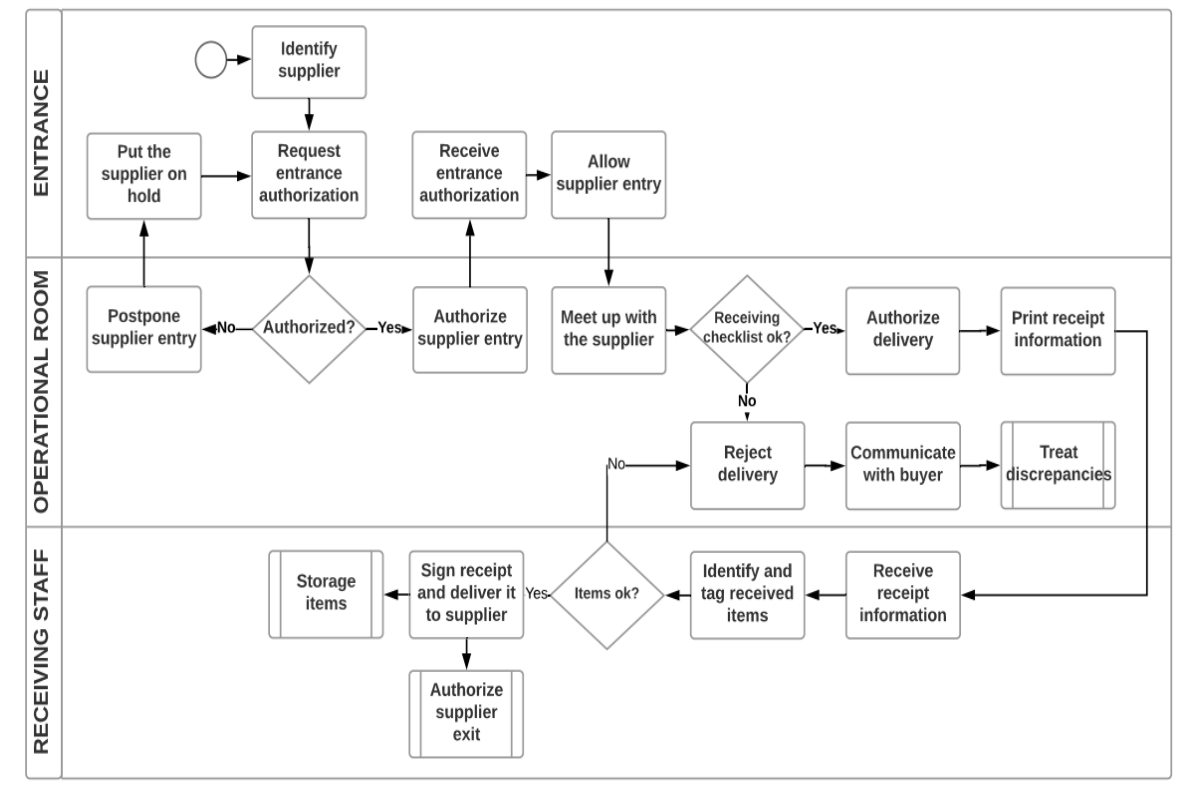

Figure 2. "As-is" flowchart representing the receiving process at the Materials warehouse. Source: Authors. 


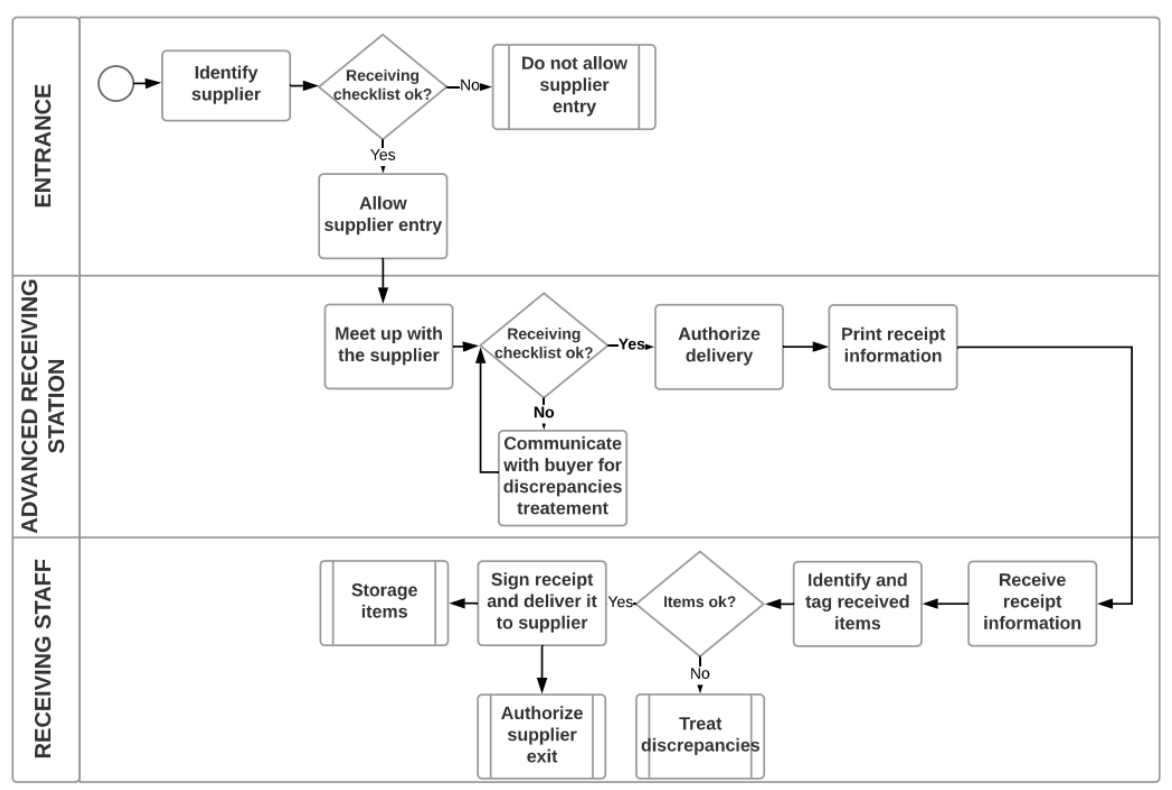

Figure 3 . "To-be" flowchart representing the receiving process at the Materials warehouse. Source: Authors.

Table 2 offers recommendations to guide a BPR process based on the synthesis conceptual model proposed in this article and in its application in the empirical study.

Table 2. Recommendations for the BPR implementation and use.

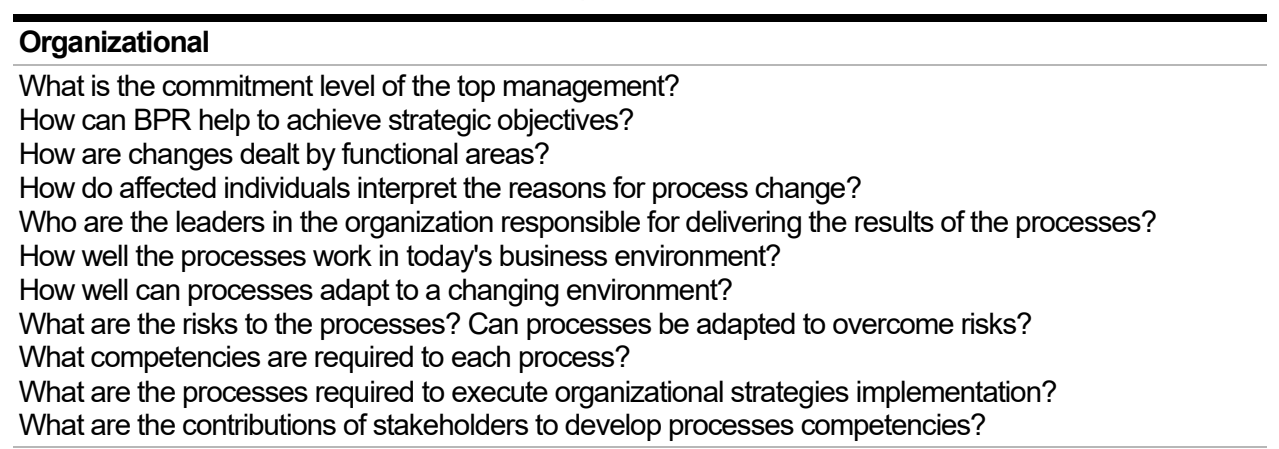

\section{Business Processes}

Why do the current processes exist and what are their goals?

Do the processes have problems?

Who are the stakeholders of the processes? What are their responsibilities?

Where do the processes fit into the organization's value chain? Do they provide value to the organization?

Do the processes support the strategic objectives of the organization?

What are the sub processes, activities and process steps?

What resources are used?

How does the information flow work?

What are the key strengths and weaknesses of processes?

Are there many steps of passing approval or inspection interfering in the main flows of processes? Is there duplication of activities performed by the same actors in the processes?

How should processes work?

What are the human and technical resources required for the new processes?

What are the goals of the BPR initiative?

What are the performance measures associated with (re)designed processes? 
Table 2. Continued...

\section{Check List}

In how many projects will the transformation initiative be subdivided?

How many teams will the project be subdivided into? Will there be team training?

How will social and technical resources be acquired? How will the interaction between social and

technical resources be? Which employees will resist change and why?

\section{Implementation}

How to ensure the transition is smooth?

What mechanisms should be established to solve unforeseen problems?

How to monitor and evaluate progress?

Where can the team find the documented processes?

Source: Authors

The governance structure for the company's process management follows the hierarchical structure of the company, where the coordinators are responsible for the processes and submit to the authority of the logistics manager, which, in turn, responds directly to the supply chain director. Monthly meetings are held between the strategic supply chain director and the logistics manager in which the results of the areas are reported. The tactical level is held monthly in logistics assessment meetings, in which the coordinators report the areas results to the manager and by e-mail to the processes stakeholders. Weekly meetings are held for the evaluation of dossiers at the operational level between the coordinators and staff areas. In all meetings the processes are criticized, the results assessed and actions for improvements are defined according to the PDCA methodology. Besides these regular meetings, event driven meetings are also held whenever a problem is detected to treat it immediately instead of waiting for the completion of the monthly meetings for their treatment and resolution.

\section{Conclusions}

The academic literature related to BPR presents a lack of structured methodologies and procedures to ensure the understanding of the transformation from the "as-is" processes to "to-be" processes. This research had as objective to present the empirical findings and lessons learned during the implementation of an action research in the logistics processes management area of a cultural production company with the objective of (re)design their processes. A synthesis conceptual model for BPR was proposed, comprising three levels: Organizational, Business Processes and Implementation. The model provides a methodological support for the transformation of current "as-is" processes in future "to-be" processes of four logistics processes management areas of a cultural production company.

The research identified the main lessons learned and barriers associated with each of the levels of the model and inherent to each of the four warehouses analysed. The lessons learned common to the three levels where the processes (re)design were successfully implemented were associated to the following factors: alignment with the business strategy, support from senior management, change management culture, collaborative environment and effective communication. The main barriers identified were the existence of a culture resistant to changes in the Special Effects warehouse and a resistance on the part of the Materials warehouse stakeholders regarding the transformation acceptance, highlighting the need for a change management assertion from the top administration in these sectors. Another barrier found was the tool incompatibility used by the IT consulting company and the BPR team for the "to-be" processes creation in the Materials, Events and Spare Parts warehouses, revealing the 
need for a greater communication among the processes stakeholders and the establishment of an organizational environment more collaborative.

The lessons learned contributed to overcome the barriers and made possible the achievement of success in the BPR project implementation. The success was achieved with the organization's ability to manage its business processes efficiently and effectively, as highlighted by the ABPMP (2013). The organization showed an improvement in the performance of its processes, which were measured by means of controlling and monitoring indicators used in the four warehouses and the human resources engagement, which were enabled by trainings conducted internally and with appropriate technologies, providing support for the implementation of the processes (re)designed. In addition, the achieved success in the implementation level was validated by the organizational culture transformation at the Special Effects warehouse, which at the beginning showed resistance to change and finally showed an operational team connected to the processes management and with a process oriented culture. The achievement of the objectives proposed in the BPR project were ratified by the company's board of directors in a closing conference conducted by the BPR team.

It is worth mentioning that, in addition to the lessons learned identified in the empirical study as essential to the success of the project, the management of the dynamism in the organizational environment was crucial to the business processes continuous improvement initiative based on current needs and business progress. In this sense, it was essential to promote an organizational culture of improvement sponsored by the top administration to ensure that the efforts to review the processes never ended by encouraging the creation of a feedback loop to ensure the maintenance of the processes besides changes in the organization's internal and external environments.

Finally, as observed in other BPR methods or structured procedures, the synthesis conceptual model developed in this article should be replicated in other empirical studies to ensure its validation in other contexts. The implementation of the synthesis conceptual model for BPR proposed did not contemplate an investigation about what occurs in transitions between the levels of the BPR methodology nor how the interactions among them are performed and which lessons learned and barriers are associated with these interactions. Therefore, it is suggested that future research on this direction to enlarge the knowledge on this aspect in BPR.

\section{References}

Abdul-Hadi, N., Al-Sudairi, A., \& Alqahtani, S. (2005). Prioritizing barriers to successful business process re-engineering (BPR) efforts in Saudi Arabian construction industry. Construction Management and Economics, 23(3), 305-315. http://dx.doi.org/10.1080/0144619042000301375.

Adesola, S., \& Baines, T. (2005). Developing and evaluating a methodology for business process improvement. Business Process Management Journal, 11(1), 37-46. http://dx.doi.org/10.1108/14637150510578719.

Albizu, E., \& Olazaran, M. (2006). BPR implementation in Europe: the adaptation of a management concept. New Technology, Work and Employment, 21(1), 43-58. http://dx.doi.org/10.1111/j.1468-005X.2006.00162.x.

Al-Mashari, M., \& Zairi, M. (1999). BPR Implementation Process: An Analysis of Key Success and Failure Factors. Business Process Management Journal, 5(1), 87-112.

http://dx.doi.org/10.1108/14637159910249108. 
Association of Business Process Management Professionals - ABPMP. (2013). BPM CBOK: Guide to the business process management common body of knowledge. Pensacola: Association of Business Process Management Professionals.

Attaran, M. (2004). Exploring the relationship between information technology and business process reengineering. Information \& Management, 41(5), 585-596. http://dx.doi.org/10.1016/S0378-7206(03)00098-3.

Berio, G., \& Vernadat, F. (2001). Enterprise modelling with CIMOSA: functional and organizational aspects. Production Planning and Control, 12(2), 128-136. http://dx.doi.org/10.1080/09537280150501239.

Carvalho, A. N., Oliveira, F., \& Scavarda, L. F. (2015). Tactical capacity planning in a real-world ETO industry case: an action research. International Journal of Production Economics, 167, 187-203. http://dx.doi.org/10.1016/j.ijpe.2015.05.032.

Carvalho, A. N., Oliveira, F., \& Scavarda, L. F. (2016). Tactical capacity planning in a real-world ETO industry case: a robust optimization approach. International Journal of Production Economics, 180, 158-171. http://dx.doi.org/10.1016/j.jpe.2016.07.019.

Carvalho, A. N., Scavarda, L. F., \& Lustosa, L. J. (2014). Implementing finite capacity production scheduling: lessons from a pratical case. International Journal of Production Research, 52(4), 1215-1230. http://dx.doi.org/10.1080/00207543.2013.848484.

Cheng, T. C. E., \& Chiu, I. S. F. (2008). Critical success factors of business process reengineering in the banking industry. Knowledge and Process Management, 15(4), 258-269. http://dx.doi.org/10.1002/kpm.316.

Coughlan, P., \& Coghlan, D. (2002). Action research for operations management. International Journal of Operations \& Production Management, 22(2), 220-240. http://dx.doi.org/10.1108/01443570210417515.

Danesh, A., \& Kock, N. (2005). An experimental study of process representation approaches and their impact on perceived modeling quality and redesign success. Business Process Management Journal, 11(6), 724-735. http://dx.doi.org/10.1108/14637150510630882.

Davenport, T. H., \& Short, J. E. (1990). The new industrial engineering: information technology and business process redesign. Sloan Management Review, 31(4), 11-27.

Dumas, M., La Rosa, M., Mendling, J., \& Reijers, H. A. (2013). Fundamentals of business process management. Berlin: Springer. http://dx.doi.org/10.1007/978-3-642-33143-5.

França, J. B. S., Netto, J. M., Barradas, R. G., Santoro, F., \& Baião, F. A. (2013). Towards knowledge-intensive processes representation. In Proceedings of the International Conference on Business Process Management Workshops (Vol. 132, pp. 126-136). USA: Springer-Verlag Berlin Heidelberg. http://dx.doi.org/10.1007/978-3-642-36285-9_14.

Furey, T. R. (1993). A six-step guide to process reengineering. Planning Review, 21(2), 20-23. http://dx.doi.org/10.1108/eb054407.

Grant, D. (2002). A wider view of business process reengineering. Communications of the ACM, 45(1), 85-90. http://dx.doi.org/10.1145/503124.503128.

Grover, V., \& Malhotra, M. K. (1997). Business process reengineering: a tutorial on the concept, evolution, method, technology and application. Journal of Operations Management, 15(3), 193-213. http://dx.doi.org/10.1016/S0272-6963(96)00104-0.

Gutierrez, D. M., Scavarda, L. F., Fiorencio, L., \& Martins, R. A. (2015). Evolution of the performance measurement system in the Logistics Department of a broadcasting company: an action research. International Journal of Production Economics, 160, 1-12. http://dx.doi.org/10.1016/j.ijpe.2014.08.012.

Hanafizadeh, P., Moosakhani, M., \& Bakhshi, J. (2009). Selecting the best strategic practices for business process redesign. Business Process Management Journal, 15(4), 609-627. http://dx.doi.org/10.1108/14637150910975561.

Harmon, P. (2014). Business process change. USA: Morgan Kaufmann. 
Harmon, P. (2015). The scope and evolution of business process management. In P. Harmon. Handbook on business process management 1 (pp. 37-81). USA: Springer-Verlag Berlin Heidelberg. http://dx.doi.org/10.1007/978-3-642-45100-3_3.

Huq, Z., Huq, F., \& Cutright, K. (2006). BPR through ERP: avoiding change management pitfalls. Journal of Change Management, 6(1), 67-85. http://dx.doi.org/10.1080/14697010500523442.

Jeston, J., \& Nelis, J. (2006). Business process management: practical guidelines to successful implementations. USA: Elsevier.

Kettinger, W. J., Teng, J. T. C., \& Guha, S. (1997). Business process change: A study of methodologies, techniques, and tools: Appendices 1-8. Management Information Systems Quarterly, 21(1), 1-40. http://dx.doi.org/10.2307/249742.

Khosravi, A. (2016). Business process rearrangement and renaming. Business Process Management Journal, 22(1), 116-139. http://dx.doi.org/10.1108/BPMJ-02-2015-0012.

Limam Mansar, S., \& Reijers, H. A. (2007). Best practices in business process redesign: use and impact. Business Process Management Journal, 13(2), 193-213. http://dx.doi.org/10.1108/14637150710740455.

Mendling, J., Reijers, H. A., \& Van der Aalst, W. M. P. (2010). Seven process modeling guidelines (7PMG). Information and Software Technology, 52(2), 127-136. http://dx.doi.org/10.1016/j.infsof.2009.08.004.

Montevechi, J. A. B., Marins, F. F., Leal, F., \& Jesus, J. T. (2008). Combined use of modeling techniques for the development of the conceptual model in simulation projects José. In S. J. Mason, R. R. Hill, L. Mönch, O. Rose, T. Jefferson, \& J. W. Fowler (Orgs.), Proceedings of the 2008 Winter Simulation Conference (pp. 987-995). USA: IEEE. http://dx.doi.org/10.1109/WSC.2008.4736165.

Morais, R. M., Kazan, S., Inês Dallavalle de Pádua, S., \& Lucirton Costa, A. (2014). An analysis of BPM lifecycles: from a literature review to a framework proposal. Business Process Management Journal, 20(3), 412-432. http://dx.doi.org/10.1108/BPMJ-03-2013-0035.

Netjes, M. (2010). Process improvement: the creation and evaluation of process alternatives (PhD thesis). Technische Universiteit Eindhoven, Eindhoven.

Paper, D., \& Chang, R.-D. (2005). The state of business process reengineering: a search for success factors. Total Quality Management \& Business Excellence, 16(1), 121-133. http://dx.doi.org/10.1080/1478336042000309907.

Parkes, A. (2016). A critical success factors model for business process implementation Taylor's Business Review, 6, 15-37.

Ranganathan, C., \& Dhaliwal, J. S. (2001). A survey of business process reengineering practice in Singapore. Information \& Management, 39(2), 125-134. http://dx.doi.org/10.1016/S03787206(01)00087-8.

Reijers, H. A. (2003). Design and control of workflow processes: business process management for the service industry. USA: Springer. http://dx.doi.org/10.1007/3-540$36615-6$

Reijers, H., \& Limanmansar, S. (2005). Best practices in business process redesign: an overview and qualitative evaluation of successful redesign heuristics. Omega, 33(4), 283306. http://dx.doi.org/10.1016/j.omega.2004.04.012.

Schackart, F. D. (2008). The benefits of implementing a parent Standard Operations Procedure (SOP) that defines the dependencies between Other SOPs and ensures product traceability. In Proceedings of the SpaceOps 2008 Conference (pp.1-23). Reston: American Institute of Aeronautics and Astronautics, Inc.

Sharp, A., \& Mcdermott, P. (2001). Workflow modeling: tools for process improvement and application development. USA: Artech House Publishers. 
Shen, C., \& Chou, C. (2010). Business process re-engineering in the logistics industry: a study of implementation, success factors, and performance. Enterprise Information Systems, 4(1), 61-78. http://dx.doi.org/10.1080/17517570903154567.

Valiris, G., \& Glykas, M. (1999). Critical review of existing BPR methodologies. Business Process Management Journal, 5(1), 65-86. http://dx.doi.org/10.1108/14637159910249117.

Van der Aalst, W. M. P., Hofstede, A. H. M., \& Weske, M. (2003). Business process management: a survey. Business Process Management, 1-12.

Vanwersch, R. J. B., Shahzad, K., Vanderfeesten, I., Vanhaecht, K., Grefen, P., Pintelon, L., Mendling, J., van Merode, G. G., \& Reijers, H. A. (2016). A critical evaluation and framework of business process improvement methods. Business \& Information Systems Engineering, 58(1), 43-53. http://dx.doi.org/10.1007/s12599-015-0417-x.

Vanwersch, R. J. B., Vanderfeesten, I., Rietzschel, E., \& Reijers, H. A. (2015). Improving business processes: Does anybody have an idea? In International Conference on Business Process Management (pp. 3-18). USA: Springer Berlin Innsbruck. http://dx.doi.org/10.1007/978-3-319-23063-4_1.

Vergidis, K., Tiwari, A., \& Majeed, B. (2006). Business process improvement using multiobjective optimisation. BT Technology Journal, 24(2), 229-235. http://dx.doi.org/10.1007/s10550-006-0065-2.

Von Rosing, M., Von Scheel, H., \& Scheer, A. W. (2014). The complete business process handbook: body of knowledge from process modeling to BPM. USA: Morgan Kaufmann.

Yoo, K., Suh, E., \& Kim, K. (2007). Knowledge flow-based business process redesign: applying a knowledge map to redesign a business process. Journal of Knowledge Management, 11(3), 104-125. http://dx.doi.org/10.1108/13673270710752144.

Zellner, G. (2011). A structured evaluation of business process improvement approaches. Business Process Management Journal, 17(2), 203-237. http://dx.doi.org/10.1108/14637151111122329.

Zellner, G. (2013). Towards a framework for identifying business process redesign patterns. Business Process Management Journal, 19(4), 600-623. http://dx.doi.org/10.1108/BPMJMar-2012-0020. 